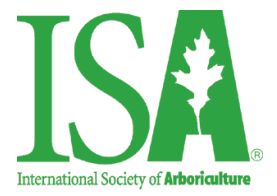

Arboriculture \& Urban Forestry 2020. 46(1):51-65

\title{
Geospatial Methods for Tree Canopy Assessment: A Case Study of an Urbanized College Campus
}

\author{
By Won Hoi Hwang and P. Eric Wiseman
}

\begin{abstract}
Urban tree canopy (UTC) assessment is essential for understanding the structure and function of urban forests and for devising management strategies. Geospatial techniques are routinely used for UTC assessment, yet their capabilities and limitations may not be apparent to urban forestry practitioners. This paper provides an overview of two primary methods of geospatial UTC assessment: photo interpretation (PI) and computerized image classification (IC). These methods were evaluated through a case study of an urbanized college campus in the eastern United States. The web-based application $i$-Tree Canopy is a PI method that uses statistical point sampling to estimate land cover. To examine the effect of point sample size on accuracy and certainty of the land cover estimates, we performed independently replicated assessments of our study area at various point sample sizes. We compared these findings with two IC methods: a proprietary analysis using high-spatial-resolution imagery and a low-spatial-resolution analysis using the web-based application $i$-Tree Landscape. With $i$-Tree Canopy, the estimate of UTC in our study area stabilized at a mean of $14.7 \%$ when point sample size reached 100 points, but it required more than 500 points to reach a tolerable standard error of less than 1.7\%. By comparison, high-resolution imagery (considered the most robust form of assessment) estimated UTC in the study area at $16.1 \%$, and $i$-Tree Landscape substantially underestimated UTC at $11.3 \%$. Possible sources of variation in these estimates, along with practical considerations for choosing an appropriate UTC assessment method, are discussed.

Keywords. Geospatial Analysis; Image Classification; i-Tree Canopy; i-Tree Landscape; Photo Interpretation; Remote Sensing; Urban Forestry; Urban Trees.
\end{abstract}

\section{INTRODUCTION}

Urban tree canopy (UTC) assessments are used to quantify the amount and distribution of tree canopy in urban areas (Nowak et al. 1996), and the data are often reported as a percentage of the total land area (Kaspar et al. 2017). Although UTC can be assessed using ground-based field measurements of trees, geospatial analysis of remotely sensed imagery (aerial and satellite photographs) is quickly taking precedent as the preferred method of UTC assessment, particularly for large geographic areas. Tree canopy cover in an urban area is strongly coupled with ecosystem services of the urban forest (Nowak and Greenfield 2012). Through ecosystem modeling, UTC data can be used to estimate carbon sequestration and storage, heat island mitigation, air pollution abatement, and stormwater runoff reduction (Dwyer et al. 1992; Xiao et al. 2000; Nowak and Dwyer 2007; Nowak et al. 2013). From an urban forest planning and management standpoint, UTC data can also be used to establish tree canopy cover goals, implement strategies to achieve such goals, and monitor progress toward them (Kimball et al. 2014).

Over the past decade, numerous institutions and organizations have performed UTC assessments in rapidly urbanizing areas across the United States. For example, the Virginia Department of Forestry commissioned a statewide project to assess UTC in 26 Virginia localities in the late 2000s (McGee et al. 2012). The Chesapeake Bay Program (a partnership of governments, nonprofits, and academic institutions) has since produced high-resolution land cover data for the entire Chesapeake Bay Watershed, covering about $260,000 \mathrm{~km}^{2}$ across six states in the eastern United States (Chesapeake Conservancy 2017). Nationally, the US Forest Service has established a partnership with the University of Vermont to form the Urban Tree Canopy Assessment Program, which has been producing tree canopy maps for urban areas across the United States (US Forest Service 2016). 
When assessing UTC using geospatial analysis of imagery, urban forestry practitioners can choose between either a photo interpretation (PI) method or a computerized image classification (IC) method. Previous studies have shown that both methods provide reliable assessments of UTC and other land cover types (Walton et al. 2008; Richardson and Moskal 2014). However, there are distinct differences in their technical accessibility and their analytical outputs that must be carefully considered by urban forestry practitioners. In this paper, we aim to help practitioners understand the capabilities and limitations of these two UTC assessment methods by first reviewing their features, then describing geospatial tools that incorporate these methods, and finally examining their practical application through a case study of an urbanized college campus in the eastern United States.

Use of geospatial analysis to perform UTC assessments has been rapidly advancing since the turn of the 21st century (Myeong et al. 2001). Compared to tree canopy measurements using conventional fieldbased techniques, which require considerable time and labor (McPherson et al. 2011), geospatial analysis provides rapid and efficient assessment of UTC and land cover across large land areas. Geospatial analysis of UTC involves detailed protocols that are technically complex and require specialized software, data, and skills (Hostetler et al. 2013). As such, small localities and nonprofit organizations may lack sufficient capabilities to assess UTC using geospatial analysis, limiting their ability to effectively monitor, plan, and manage their urban forests.

The US Forest Service has sought to eliminate these barriers by creating two web-based UTC assessment tools for public use: i-Tree Canopy (http://canopy.itreetools.org) and i-Tree Landscape (http:// landscape.itreetools.org). These two applications offer contrasting approaches to UTC assessment: $i$-Tree Canopy is a PI method, and i-Tree Landscape is an IC method. With i-Tree Canopy, a point sampling protocol is incorporated into a Google $\mathrm{Maps}^{\mathrm{TM}}$ interface, allowing users to view land cover across an area and to calculate the percentage of predetermined land cover types. With i-Tree Landscape, users are provided a mapping interface to query preclassified land cover maps obtained from the 2011 National Land Cover Database (NLCD). Although their assessment outputs are similar, there are fundamental differences in how these applications generate data and how their assessments might be utilized for urban forest planning and management.

Urban forestry practitioners must understand the differences between the PI and IC methods of UTC assessment so that they can choose the appropriate tool for their analysis needs. The PI method requires an analyst to visually examine randomly sampled points on an aerial or satellite photo and then classify the land cover for each point (Nowak et al. 1996). Although PI offers a faster and more technically straightforward UTC assessment than IC, there are limitations to PI data outputs. More specifically, PI can estimate the percentage of UTC and other land cover types in a particular area, but it cannot capture the distribution or connectivity of these cover types across the landscape. In addition, because PI uses statistical sampling, the accuracy and certainty of UTC and land cover estimates from PI depends on the sample size (number) of PI points evaluated in a study area. Any estimate derived using a sampling protocol has an associated margin of error (typically calculated as a standard error), which indicates the degree of uncertainty associated with the estimate (Nowak et al. 1996; Nowak and Greenfield 2012). This uncertainty is often communicated with a confidence interval around the estimate, which is calculated using the standard error and shows the amount of deviation one might expect in the estimate upon repeated sampling with some degree of statistical confidence (usually $95 \%$ confidence).

To generate an accurate UTC estimate and minimize the associated standard error, a sufficient point sample size is needed for a PI method such as $i$-Tree Canopy; the more sample points that are interpreted, the closer the estimate is to the "true" value and the lower the standard error of that estimate (Nowak et al. 1996; Nowak and Greenfield 2012). However, adding more interpretation points to the UTC assessment requires additional time and cost. Therefore, determining an optimal sample size (not more or less than needed) can help urban forestry practitioners to use PI for UTC assessments in a rapid and efficient manner.

Another potential source of error in PI is visual misinterpretation of the photos that are being point sampled by the analyst, resulting in erroneous classification of the land cover. Interpretation errors may be caused by edges, shadows, and vegetation height (Parmehr et al. 2016). These errors can be minimized by providing adequate training to analysts and by 
using high-resolution images that make it easier to discriminate trees from other land cover types (Richardson and Moskal 2014). These same sources of error, discussed in greater detail later, can also be troublesome for the IC method.

There are two primary differences between the IC method and the PI method of UTC assessment. First, IC is a census of every pixel in the imagery rather than a sample of representative areas within the imagery. As such, a "wall-to-wall" land cover classification map is obtained for the study area. While there may be errors in classification of the pixels (described later), every pixel is classified, and there is no statistical sampling error as with the PI method. The second difference is that the IC method relies on spectral analysis by computer algorithms rather than on the visual acuity of a human analyst to classify the land cover in the imagery. Once an algorithm is properly "trained" to distinguish land cover types, it can be deployed to autonomously analyze and classify the land cover of every pixel in the imagery (Myeong et al. 2001), making wall-to-wall classification feasible for very large land areas. It is important to note here that $i$-Tree Landscape, although considered an IC method in the scope of this paper, does not perform this computerized classification of land cover in real time. Rather, it simply displays the land cover maps that have been previously created and then provides an interface to query this land cover for a user-defined study area.

Although it is more technically complex to program and train algorithms, the resulting wall-to-wall IC is much richer in information content because it not only calculates the amount of UTC but also the distribution of UTC across the study area. When combined with other types of geospatial data (e.g., population demographics), an IC assessment also affords opportunities for complex geospatial analysis of the urban ecosystem. Some of these capabilities are built into $i$-Tree Landscape and provide a powerful decision-support tool for practitioners.

The IC method of UTC assessment is not without limitations. Consideration must be given to the specification of the imagery used in the analysis - such as its geometric, spatial, and temporal resolutionsbecause this can significantly affect the IC quality (Campbell and Wynne 2011). Spatial resolution is particularly important. Previous studies found that the 2001 NLCD (30-m spatial resolution) underestimated tree canopy in urban areas by up to $28.4 \%$ locally (Greenfield et al. 2009; Nowak and Greenfield 2010). The 2001 NLCD had limited detection capabilities for urban tree canopy because a single pixel, covering an area of $900 \mathrm{~m}^{2}$, may contain a combination of land cover types (called a mixed pixel), preventing accurate detection and differentiation of tree canopy from other cover types (Landry and $\mathrm{Pu} 2010$ ).

Although the 2011 NLCD used in i-Tree Landscape has improved capabilities for UTC assessment, the spatial resolution is still coarse $(30 \mathrm{~m})$, and mixed pixels remain a challenge to accuracy. Most proprietary IC assessments of UTC performed by contractors or scientists use high-resolution (1 $\mathrm{m}$ or less) imagery and advanced geospatial techniques (e.g., object-based image analysis) that improve accuracy of UTC assessments (MacFaden et al. 2012; McGee et al. 2012; O'Neil-Dunne et al. 2014). In addition, high-resolution imagery is increasingly combined with LiDAR (Light Detection and Ranging) data, which provides height information for ground-based objects and can help to discriminate between trees, shrubs, and tall grass (MacFaden et al. 2012; Ucar et al. 2016). These advanced techniques require specialized knowledge of remote sensing to process and analyze the data for generating statistics about UTC coverage (Walton et al. 2008) and are all important considerations for practitioners who may wish to obtain a proprietary IC assessment of UTC from a contractor. While i-Tree Landscape takes away some of these concerns for the practitioner, it is still important to recognize that $i$-Tree Landscape incorporates mostly low-resolution imagery, and the land cover classification maps it displays are likely to underestimate UTC. High-resolution land cover maps are being added incrementally to the application and will improve its capabilities over time.

In the following sections of this paper, we present a case study in which we examine these geospatial methods for assessing UTC on an urbanized college campus in the eastern United States. For the case study, we first conducted a series of replicated UTC assessments using the PI method found in $i$-Tree Canopy. There we analyzed the effect of the point sample size on the accuracy and estimation error for UTC and other land cover types. We then compared these findings with two UTC assessments that were performed using the IC method: a proprietary analysis using highspatial-resolution imagery and a low-spatial-resolution 
analysis found in i-Tree Landscape. Advantages and disadvantages of all three methods are discussed.

\section{METHODS}

\section{Study Area}

Our study area was the campus of Virginia Tech, located in Blacksburg, VA. It is a moderately urbanized area in the Ridge and Valley physiographic province of the eastern United States, and the natural forest cover type in this area is oak-hickory (Eyre 1980). Tree cover on the campus is predominantly transplanted trees of assorted native and nonnative species situated in open lawns, parking lot islands, and street-side planting strips. Remnant forest fragments $(<6$ ha) and riparian buffers comprise less than $10 \%$ of the land area. A complete inventory conducted in 2017 determined that there are 225 different tree species on the campus. The most prevalent species are Acer saccharum Marsh. (6\%), Pinus strobus L. (5\%), Acer rubrum L. (4\%), and Quercus rubra L. (4\%). About $40 \%$ of the campus trees are $23 \mathrm{~cm}$ to $61 \mathrm{~cm}$ in trunk diameter. For this study, we selected about $3.58 \mathrm{~km}^{2}$ of central campus (the urbanized core) to examine geospatial methods for UTC assessment (Figure 1).

\section{Computerized Image Classification (IC) Method}

Our first IC assessment of UTC entailed a proprietary analysis of high-resolution imagery for the study area obtained during a project commissioned by the Virginia
Department of Forestry. This project conducted assessments in 26 Virginia localities and assessed UTC with over $90 \%$ accuracy using a proprietary classification protocol on the 2008 National Agriculture Imagery Program (NAIP) imagery (1-m spatial resolution with four spectral bands: three visible and one near-infrared; McGee et al. 2012; USDA 2015). The protocol started with an ISODATA unsupervised IC. Image pixels were clustered into 200 spectral classes and then visually assigned to one of seven initial land cover types (water, structure impervious surface, nonstructure impervious surface, nontree vegetation, tree canopy, shadow, and mixed). After the initial IC, two classes (shadow and mixed) were reclassified and manually assigned into one of the final land cover classes, which were the same used in the PI-based assessments: water (WA), impervious surface (IS), nontree vegetation (NTV), and tree canopy (TC). Once IC was complete, an accuracy assessment was performed by cross-referencing with 100 random points using the Virginia Base Mapping Program imagery, which was available statewide in three high-spatial resolutions: $8 \mathrm{~cm}, 15 \mathrm{~cm}$, and $30 \mathrm{~cm}$ (Virginia Information Technologies Agency 2016). Manual edits of misclassified points were performed until an overall accuracy of greater than $90 \%$ was achieved. Detailed information about the protocol is available in McGee et al. (2012).

Our campus study area was captured in a proprietary UTC analysis performed for the adjacent Town
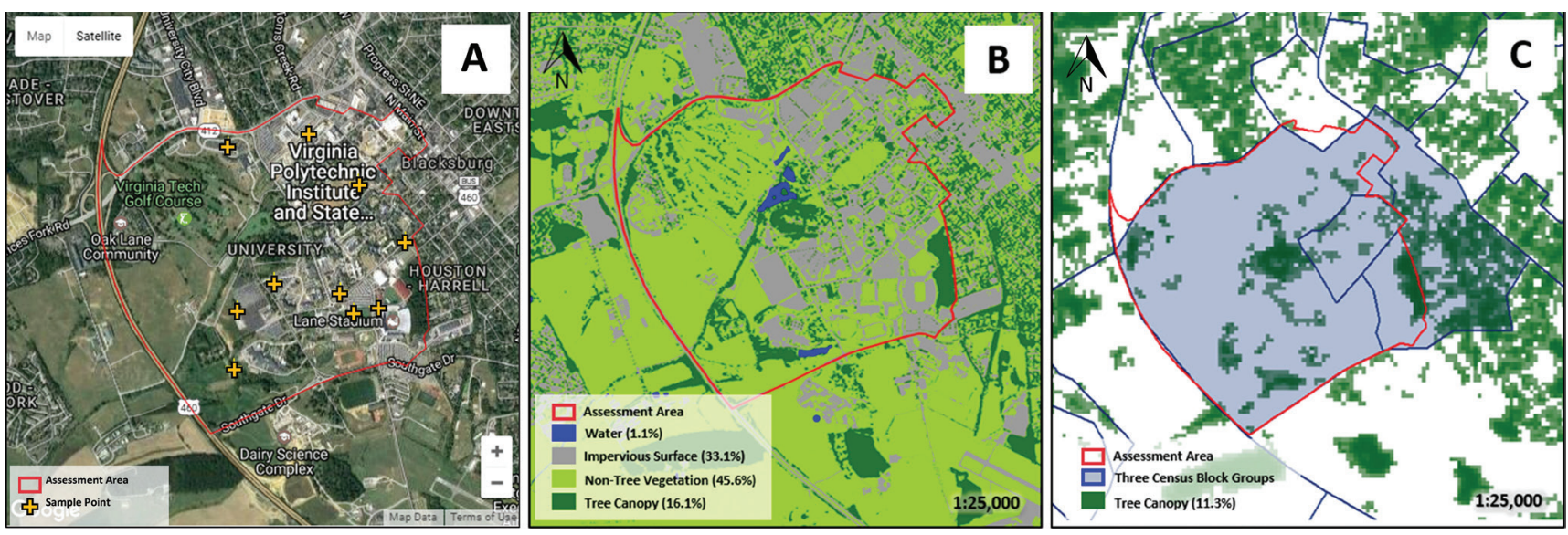

Figure 1. Map scenes from three geospatial methods of tree canopy assessment evaluated on the Virginia Tech campus in Blacksburg, VA. Panel A: Screenshot from $i$-Tree Canopy, a PI web application, showing a randomization of ten sample points across the study area. Panel B: Screenshot of a computerized IC of land cover types from a high-resolution image (proprietary analysis) of the study area. Panel C: Screenshot from i-Tree Landscape showing the tree canopy cover classified from a low-resolution image of three US Census Block Groups overlaying the study area. The study area was $3.58 \mathrm{~km}^{2}$, and the three Census Block Groups (blue-shaded area in Panel C) covered $4.52 \mathrm{~km}^{2}$. 
of Blacksburg (Figure 1B). Using ArcMap ${ }^{\circledR}$ Version 10 (Esri, Redlands, CA), we clipped our study area out of the land cover map and calculated the area comprising each of the same four land cover classes used in our i-Tree Canopy analysis.

Our second IC assessment of UTC entailed land cover classification from low-resolution imagery in $i$-Tree Landscape. Knowing that the land cover data derived from 2011 NLCD is much coarser than the data in the proprietary high-resolution analysis, we were interested to see how they compared for our campus study area. An analysis limitation of $i$-Tree Landscape is that the user cannot delineate a precise study area on the application's web map. Instead, the user must choose a boundary from a library of several predetermined boundary types. The boundary that most closely overlaid our campus study area was the selection of three contiguous US Census Block Groups, which is the smallest scale boundary-delimiting scheme built into the application. This resulted in an analysis area of $4.52 \mathrm{~km}^{2}$ that encompassed some nonuniversity residential and commercial land on the east side of campus and was larger than the primary study area of $3.58 \mathrm{~km}^{2}$ (Figure 1C). Therefore, for a more direct comparison of the UTC estimate between the analysis methods, we took additional steps outside of $i$-Tree Landscape to clip out our study area from the 2011 NLCD US Forest Service tree canopy data (US Geological Survey 2017). This is a raster dataset embedded in i-Tree Landscape where each pixel in the map represents the percent of tree cover for a 30-m spatial-resolution pixel. For example, a pixel with a value of 30 means that tree canopy covers $30 \%$ of the $900 \mathrm{~m}^{2}$ area $(30 \mathrm{~m} \times 30 \mathrm{~m})$.

\section{Photo Interpretation (PI) Method}

For our PI method, we used the web-based application i-Tree Canopy (Figure 1A). In using this application, the analyst is led through a series of steps to (1) define the assessment area on the aerial photo, (2) define the land cover classes to be assessed, and (3) randomize and visually interpret sampling points on the aerial photo. As the analyst classifies the land cover of each randomized point on Google $\mathrm{Maps}^{\mathrm{TM}}$, the application keeps a running total of sample size, percent of land area in each cover class, and the standard error associated with each cover class estimate. The assessment is concluded when the analyst completes a predetermined point sample size.
Our aim was to examine the effect of increasingly larger point sample sizes on the resultant land cover estimates and associated standard errors; therefore, we analyzed eight different point sample sizes. Based on recommendations provided on the $i$-Tree Canopy website, we started with sample sizes of 500 and 1,000 points (US Forest Service 2011). These equated to point sampling intensities in our study area (3.58 $\mathrm{km}^{2}$ ) of about 139 and 278 points per $\mathrm{km}^{2}$, respectively. We then chose six additional point sample sizes (sampling intensities) that bracketed the average sampling intensity ( 4.1 points per $\left.\mathrm{km}^{2}\right)$ reported in a UTC study of 20 U.S. cities (Nowak and Greenfield 2012). These point sample sizes (\# per $\mathrm{km}^{2}$ ) were 10 (2.8), 12 (3.3), 25 (6.9), 50 (13.9), 100 (27.8), and 250 (69.4). For each of the eight sample sizes, we conducted ten independently replicated runs of $i$-Tree Canopy for our study area. All replicated runs were conducted by a primary analyst who had extensive experience working with aerial photos and a high level of familiarity with the campus landscape features.

We predefined four land cover classes for PI of our study area: water (WA), impervious surface (IS), nontree vegetation (NTV), and tree canopy (TC). We also included a category for uninterpretable points, to which we assigned sample points that fell onto shadow areas or at the edge between two land cover types. Two additional analysts independently reviewed the uninterpretable points and assigned them into one of the four land cover classes. When these two analysts did not agree, the primary analyst made a final decision for classification.

The three geospatial methods for this study used imagery that was collected in two different time frames: the high-resolution imagery analysis (proprietary IC method) used 2008 NAIP imagery, the low-resolution imagery analysis (i-Tree Landscape) used 2011 NLCD canopy cover maps, and the PI method (i-Tree Canopy) used 2011 to 2012 Google $\mathrm{Maps}^{\mathrm{TM}}$ imagery. Although we were limited to the imagery that was available through each analysis method, the only way we could address the differing dates was to conduct additional PI-based assessments using ArcGIS $^{\circledR}$ (five replications with 500 sample points each on the 2008 NAIP image) to examine differences in tree cover in the study area between 2008 and 2011. 


\section{Statistical Analysis}

All statistical analyses were performed using JMP ${ }^{\circledR}$ Version 9 (SAS Institute Inc., Cary, NC). Descriptive statistics were calculated for each replicated sample size scheme in $i$-Tree Canopy. We then compared the land cover estimates from each sample size scheme in $i$-Tree Canopy to the land cover estimates obtained from the proprietary high-resolution assessment. Statistical comparisons were made using one-sample t-tests between the individual land cover class estimates and Chi-square tests to examine the relative distribution of land cover percentages. The null hypothesis of no difference in land cover estimates and distribution of land cover percentages between the methods was tested at the $\alpha=0.05$ significance level.

\section{RESULTS}

\section{Tree Canopy Estimates Using the PI Method}

A challenge of comparing UTC assessment methods in this study was the varying dates of aerial imagery capture. Because we were interested in comparing the accuracy of the i-Tree Canopy PI assessment (2011 imagery) and the proprietary high-resolution IC assessment (2008 imagery), we first sought to confirm that there were no differences in UTC between the two dates attributable solely to change in time. When we compared five independent replications of a 500-point PI sample of the 2008 NAIP imagery to the same scheme using 2011 imagery in $i$-Tree Canopy, we found no statistically significant difference in UTC between the two: the 2008 NAIP imagery $(M=15.9$, $S D=2.03)$ and the 2011 imagery in $i$-Tree Canopy $(M=14.5, S D=1.30), P=0.117$.

In looking at the land cover estimates for our study area obtained from the eight sampling schemes replicated in $i$-Tree Canopy, the overall average land cover was $1.0 \%$ WA, $38.2 \%$ IS, $45.8 \%$ NTV, and $14.7 \%$ TC (Table 1). Across the land cover classes, the mean estimates were highly variable until the sample size approached 100 points ( 27.8 points per $\mathrm{km}^{2}$ ); thereafter, they started to stabilize. In particular, tree cover was the most variable of the nonwater classes; the coefficient of variation remained above $30 \%$ until sample size reached 100 points. As the sample size

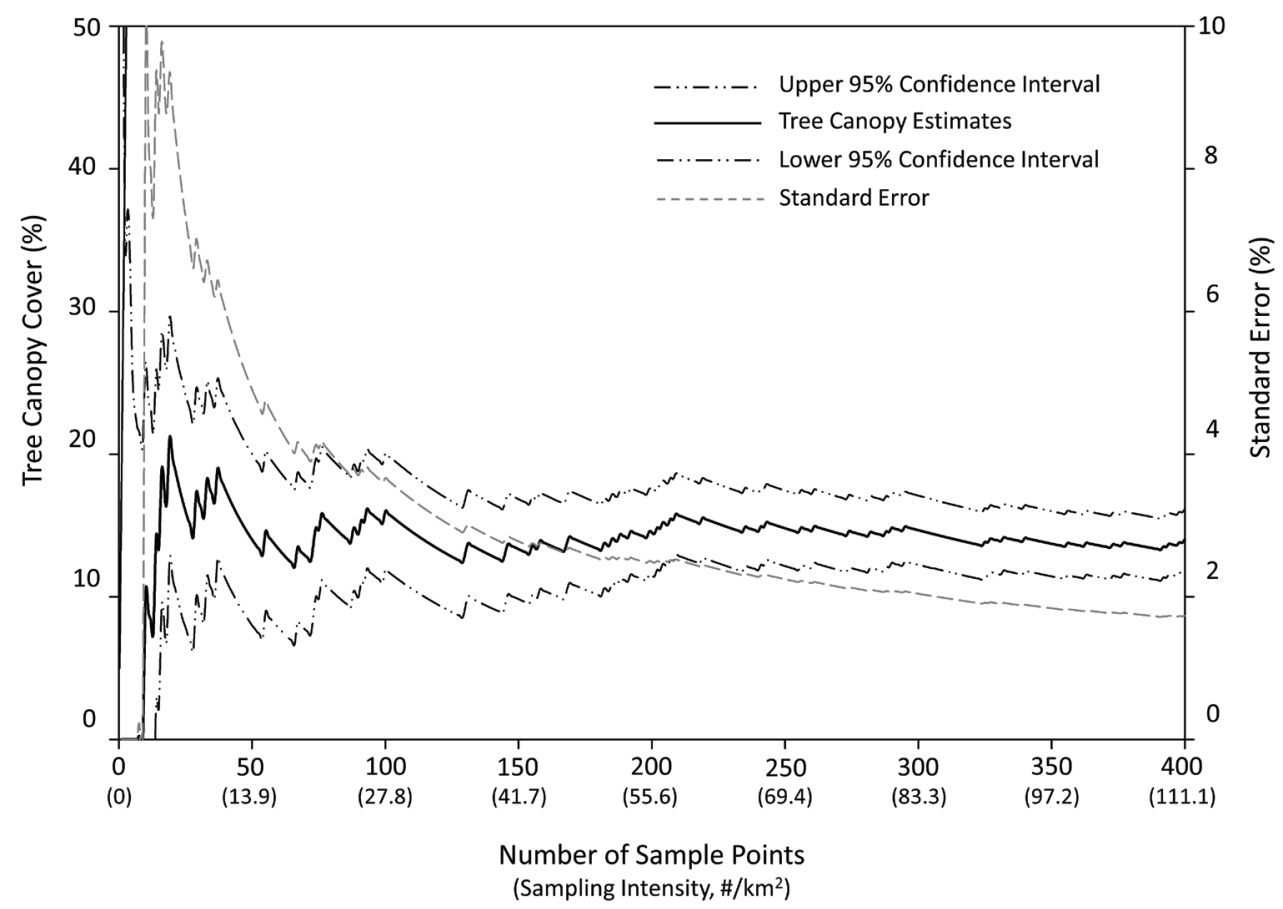

Figure 2. The relationship between the sample size of PI points, tree canopy cover estimate ( $\%$ of land area), and standard error of the tree canopy cover estimate (\%) on the Virginia Tech campus in Blacksburg, VA (3.58 km2 study area). The tree canopy cover estimate (solid line) was highly variable until the sample size approached 100 points (28 points per $\mathrm{km} 2$ ) and stabilized around $15 \%$ thereafter. Beyond the sample size of 250 points (69 points per km2), there was little difference in the tree canopy cover estimate, but the standard error (gray hatched line) continuously decreased. Data depicted in the graph are taken from independently replicated runs of $\mathrm{i}$-Tree Canopy ranging in sample size from 10 to 1,000 points (only first 400 points shown). 
Table 1. Descriptive statistics for assessments of tree canopy and other land cover types on the Virginia Tech campus in Blacksburg, Virginia using photo interpretation in i-Tree Canopy. For each of the eight sample size schemes, there were ten independently replicated runs of $i$-Tree Canopy for the study area $\left(3.58 \mathrm{~km}^{2}\right)$.

\begin{tabular}{|c|c|c|c|c|c|c|c|c|c|c|c|c|c|c|c|c|}
\hline & \multicolumn{4}{|c|}{ Water (WA) } & \multicolumn{4}{|c|}{ Impervious Surface (IS) } & \multicolumn{4}{|c|}{ Non-Tree Vegetation (NTV) } & \multicolumn{4}{|c|}{ Tree Canopy (TC) } \\
\hline $\begin{array}{l}\text { Sample size } \\
\text { scheme }^{\mathrm{a}}\end{array}$ & \multicolumn{4}{|c|}{10 points $\left(2.8 / \mathrm{km}^{2}\right)$} & \multicolumn{4}{|c|}{12 points $\left(3.3 / \mathbf{k m}^{2}\right)$} & \multicolumn{4}{|c|}{25 points $\left(6.9 / \mathrm{km}^{2}\right)$} & \multicolumn{4}{|c|}{50 points $\left(13.9 / \mathrm{km}^{2}\right)$} \\
\hline $\operatorname{Min}^{\mathrm{b}}(\%)$ & 0.0 & 10.0 & 30.0 & 0.0 & 0.0 & 16.7 & 25.0 & 8.3 & 0.0 & 20.0 & 36.0 & 4.0 & 0.0 & 32.0 & 34.0 & 10.0 \\
\hline $\operatorname{Mean}^{\mathrm{b}}(\%)$ & 0.0 & 36.0 & 45.0 & 18.0 & 0.8 & 31.7 & 50.0 & 17.1 & 0.8 & $41.2^{*}$ & 45.2 & 12.8 & 0.8 & $42.2^{* * *}$ & 43.0 & 14.0 \\
\hline $\operatorname{Max}^{\mathrm{b}}(\%)$ & 0.0 & 60.0 & 80.0 & 40.0 & 8.3 & 50.0 & 75.0 & 41.7 & 4.0 & 56.0 & 64.0 & 28.0 & 2.0 & 52.0 & 52.0 & 22.0 \\
\hline $\mathrm{SD}^{\mathrm{c}}$ & 0.0 & 16.5 & 19.0 & 12.3 & 2.6 & 10.2 & 14.0 & 10.3 & 1.7 & 11.3 & 8.9 & 7.5 & 1.0 & 6.1 & 5.8 & 4.2 \\
\hline $\mathrm{CV}^{\mathrm{c}}$ & 0.0 & 45.7 & 42.2 & 68.3 & 0.0 & 32.4 & 29.1 & 61.3 & 210.8 & 27.5 & 19.6 & 58.6 & 129.1 & 14.4 & 13.6 & 30.2 \\
\hline $\operatorname{Min}(\%)$ & 0.0 & 25.0 & 36.0 & 9.0 & 0.4 & 35.2 & 42.8 & 11.6 & 0.0 & 34.4 & 43.8 & 12.4 & 0.7 & 36.5 & 42.9 & 13.4 \\
\hline Mean (\%) & 0.0 & $36.0^{*}$ & 48.0 & 14.0 & 1.0 & $38.8^{* * *}$ & 45.8 & $14.4^{*}$ & 0.9 & $38.4^{* * *}$ & 46.3 & $14.5^{* *}$ & 1.1 & $38.0^{* * *}$ & 45.4 & $14.9^{* *}$ \\
\hline $\operatorname{Max}(\%)$ & 3.0 & 46.0 & 62.0 & 18.0 & 2.0 & 42.0 & 47.6 & 16.4 & 1.4 & 41.8 & 50.0 & 17.2 & 1.8 & 40.4 & 47.2 & 15.8 \\
\hline SD & 1.0 & 6.1 & 7.6 & 2.5 & 0.5 & 2.4 & 1.7 & 1.8 & 0.4 & 2.0 & 1.8 & 1.3 & 0.3 & 1.3 & 1.2 & 0.9 \\
\hline $\mathrm{CV}$ & 161.0 & 16.9 & 15.5 & 17.8 & 54.2 & 6.2 & 3.7 & 12.6 & 51.5 & 5.2 & 3.9 & 9.0 & 29.2 & 3.4 & 2.7 & 6.0 \\
\hline
\end{tabular}

${ }^{a}$ Shown are the number of sample points $(\mathrm{N})$ and the sampling intensity $\left(\mathrm{N}\right.$ per $\mathrm{km}^{2}$ of study area).

${ }^{\mathrm{b}}$ Minimum, mean, and maximum run values derived from ten independently replicated runs of $i$-Tree Canopy for each sample size scheme.

${ }^{c} \mathrm{SD}$ (sample standard deviation) and CV (coefficient of variation: mean $\div$ std. dev. $\times 100$ ) of the ten replicates for each sample size scheme.

Asterisks $(*)$ indicate a significant difference between the mean land cover values of a given sample size scheme and the land cover values derived from a

computerized classification of high-resolution imagery (shown in Table 2) using one-sample $t$-tests $\left({ }^{*} p<0.05 ;{ }^{* *} p<0.01 ;{ }^{* * *} p<0.001\right.$ ).

increased, ranges between the minimum and maximum land cover values (from ten replicated runs) decreased and narrowed around the mean land cover values. At sample sizes beyond 250 points, there were no substantial changes in the mean values of land cover estimates (estimator accuracy), but variation (error) in the estimates steadily diminished, as evidenced by the progressively smaller standard deviation and coefficient of variation.

As expected, the choice of point sample size influenced the accuracy of our UTC estimates and the associated standard errors (Figure 2). At sample sizes below 100 points, the UTC estimate from replicated runs of $i$-Tree Canopy was highly variable, ranging from $0 \%$ to $21 \%$, and standard error of the estimate neared $10 \%$. As sample size approached 100 points, the UTC estimate began to stabilize around $15 \%$, and the standard error dropped precipitously to less than $4 \%$. Further increase in sample size beyond 100 points did not markedly change the UTC estimate, but the variability became minimal, and the UTC estimate appeared to stabilize around $14 \%$ to $15 \%$. Standard error continued to decline with increasing sample size, and the bounds of the $95 \%$ confidence interval tightened around the UTC estimate. Qualitatively speaking about UTC estimation accuracy and error control, there were major improvements by increasing sample size to 100 points $(27.8$ points per $\mathrm{km}^{2}$ ) and moderate improvements by further increasing sample size to 250 points (69.4 points per $\mathrm{km}^{2}$ ). Beyond 250 points, the UTC estimate did not improve, but confidence in the estimate continued to improve.

\section{Comparing Tree Canopy Estimates of the PI and IC Methods}

UTC and land cover estimates for the study area derived from all three geospatial methods of analysis are shown in Table 2. Compared with the IC method 
Table 2. Comparison of assessments of tree canopy and other land cover types on the Virginia Tech campus in Blacksburg, Virginia using a photo interpretation (PI) method (i-Tree Canopy) and two computerized image classification (IC) methods: high-resolution imagery (proprietary analysis) and low-resolution imagery (i-Tree Landscape).

\begin{tabular}{|c|c|c|c|c|c|c|c|}
\hline & \multirow{3}{*}{$\begin{array}{c}\text { PI method } \\
\begin{array}{c}\text { Study area } \\
\text { tree canopy }\end{array}\end{array}$} & \multicolumn{6}{|c|}{ IC methods } \\
\hline & & \multicolumn{4}{|c|}{ High-resolution imagery (1 m) } & \multicolumn{2}{|c|}{ Low-resolution imagery $(30 \mathrm{~m})$} \\
\hline & & $\begin{array}{l}\text { Study area } \\
\text { water }\end{array}$ & $\begin{array}{c}\text { Study area } \\
\text { impervious } \\
\text { surface }\end{array}$ & $\begin{array}{c}\text { Study area } \\
\text { non-tree } \\
\text { vegetation }\end{array}$ & $\begin{array}{l}\text { Study area } \\
\text { tree canopy }\end{array}$ & $\begin{array}{l}\text { Census block } \\
\text { tree canopy }^{\mathrm{c}}\end{array}$ & $\begin{array}{l}\text { Study area } \\
\text { tree canopy }\end{array}$ \\
\hline Land cover estimate & $14.7 \%$ & $1.1 \%$ & $31.1 \%$ & $45.6 \%$ & $16.1 \%$ & $11.3 \%$ & $6.7 \%$ \\
\hline Producer's accuracy ${ }^{\mathrm{a}}$ & - & $100.0 \%$ & $100.0 \%$ & $90.2 \%$ & $96.9 \%$ & - & - \\
\hline User's accuracy ${ }^{\mathrm{a}}$ & - & $100.0 \%$ & $89.8 \%$ & $97.4 \%$ & $96.9 \%$ & - & - \\
\hline Overall accuracy & - & \multicolumn{4}{|c|}{$96.0 \%$} & \multicolumn{2}{|c|}{ - } \\
\hline
\end{tabular}

a Producer's accuracy indicates the probability that a pixel is correctly classified by the computer algorithm while user's accuracy measures the probability that a classified pixel actually matches what it is on the ground (Campbell and Wynne 2011).

${ }^{b}$ Weighted mean of ten independently replicated runs of $i$-Tree Canopy at varying point sample sizes (see Table 1).

'Tree canopy cover estimate derived from $i$-Tree Landscape using three Census Block Groups that overlapped the study area $\left(4.51 \mathrm{~km}^{2}\right)$.

${ }^{d}$ Tree canopy cover estimate for the study area $\left(3.58 \mathrm{~km}^{2}\right)$ manually extracted from the 2011 NLCD USFS Tree Canopy data that comprises $i$-Tree Landscape.

of high-resolution imagery analysis that achieved an overall accuracy of $96.0 \%$, the PI method (i-Tree Canopy) underestimated UTC by an absolute difference of $1.4 \%$, averaged across all point sample size schemes. This equates to about 5 ha of tree canopy across the study area - a very small but not inconsequential amount of tree canopy. One-sample t-tests showed that statistically significant differences persisted in UTC and impervious surface values between the two methods even at large point sample sizes. Due to high variability among replicated runs, the statistical test did not detect a significant difference in the mean UTC estimate at the sample size of 100 points $(P=0.052)$. High variability likewise impacted the power of the statistical test for smaller sample size schemes. Regardless of statistically significant differences, the magnitude of differences in UTC between the two (particularly at large point sample sizes) would be inconsequential for most practical applications of land cover assessment.

Looking at the overall distribution of land area across the four cover classes, the Chi-square distribution test found no statistical difference between the PI method and the high-resolution IC method at a point sample size of 250 or larger (all $P>0.05$ ). Despite the close agreement of those two methods, the IC method of low-resolution imagery analysis (i-Tree Landscape) substantially underestimated tree canopy cover in the study area, with UTC values $8 \%$ and
9.4\% lower than $i$-Tree Canopy and high-resolution IC, respectively. This equates to $i$-Tree Landscape effectively missing about 29 ha and 34 ha, respectively, of UTC in the study area.

\section{DISCUSSION}

\section{Minimum Point Sample Size for the PI Method}

Our analysis confirms that gains in accuracy and certainty of UTC and land cover estimates when using a PI method such as i-Tree Canopy can be realized when point sample size is increased. The key to conducting an efficient PI-based UTC assessment is understanding the interplay between assessment area size, point sample size, and canopy cover distribution in the assessment area. The goal is to choose the minimum point sample size to achieve an accurate estimate of UTC with a tolerable error rate.

Theoretically, the minimum point sample size depends upon the amount of UTC in an area and the tolerable error of the UTC estimate (Parmehr et al. 2016; Ucar et al. 2016). To achieve a standard error of less than $1.6 \%$ for the UTC estimate (considered a quality benchmark), the $i$-Tree Canopy website recommends a sample size between 500 and 1,000 points (US Forest Service 2011), assuming that a typical-sized locality with typical UTC distribution is being assessed. A study of Seattle, WA, by Richardson 

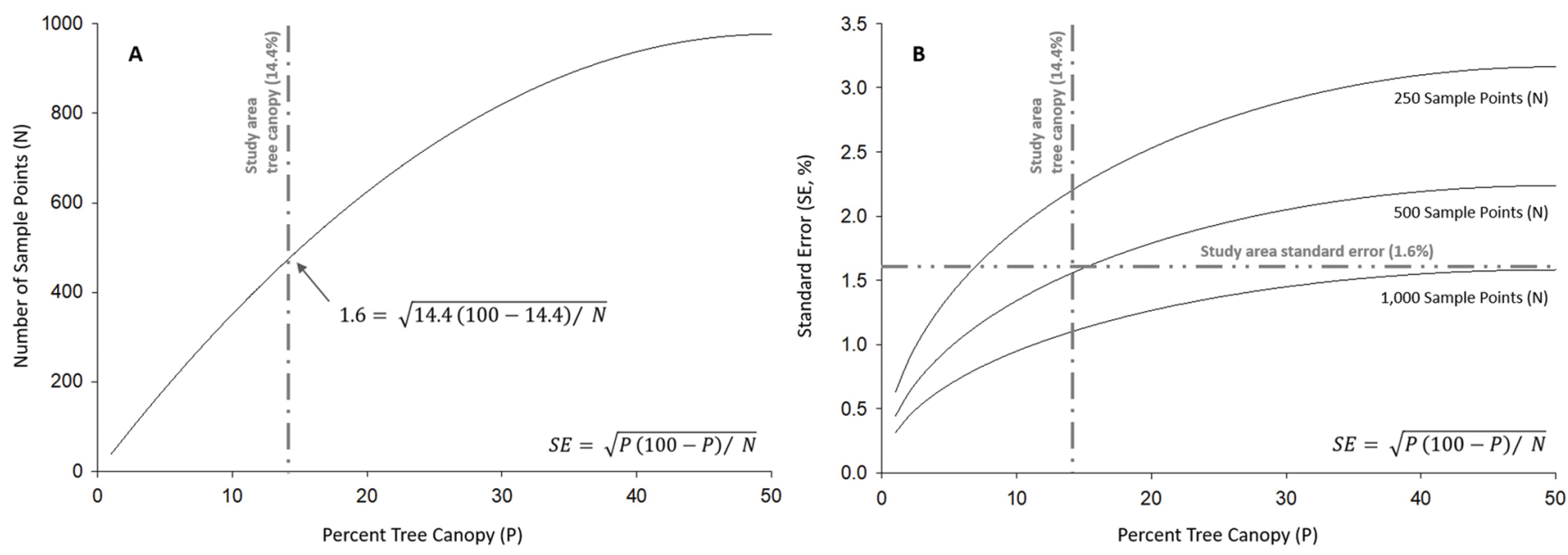

Figure 3. The relationship between the sample size of PI points (N), tree canopy cover (P, expressed as \% of land area), and standard error of the tree canopy cover estimate (SE, expressed as \%). Panel A shows the point sample size necessary to yield a standard error of $1.6 \%$ (a common benchmark for reliability of the estimate) given the actual amount of tree canopy cover that exists in a given study area. Panel B shows how increasing the point sample size drives down the standard error of a tree canopy cover estimate, particularly at relatively low levels of existing tree canopy cover $(<15 \%)$. Gray hatched lines on both panels denote the canopy cover estimate and standard error derived for our study area on the Virginia Tech campus in Blacksburg, VA, using $i$-Tree Canopy.

and Moskal (2014) found that the UTC estimate stabilized around $28.5 \%$ with a standard error of $1.7 \%$ when 700 or more sample points were interpreted (sampling intensity of 3.2 points per $\mathrm{km}^{2}$ or more). In our study area, the UTC estimate began to stabilize around $14.0 \%$ with a standard error of $3.5 \%$ when 100 or more sample points were interpreted (sampling intensity of 27.8 points per $\mathrm{km}^{2}$ or more), but it required 500 or more points to achieve a standard error of less than $1.7 \%$. Since Seattle is 100 times larger in size and its UTC is roughly double that of our study area, this comparison shows that the minimum point sample size depends more so on the amount of UTC in the assessed area than on the size of the assessed area.

Figure 3 shows the interplay of variables affecting the error rate in a UTC and land cover assessment. The graph in Figure 3A shows that a study area with $20 \%$ tree canopy would require an analyst to review about 600 sample points to achieve a standard error of $1.6 \%$. If the analyst increases the sample size up to 1,000 points, the standard error of the UTC estimate decreases to $1.2 \%$ (Figure 3B). A study at West Virginia University used $i$-Tree Canopy to assess UTC in 17 localities (Walker et al. 2017). With a target standard error of $5.0 \%$, they interpreted 500 sample points per locality. Their UTC estimates ranged from $23.6 \%$ to $57.0 \%$ with associated standard errors of $1.9 \%$ to
$2.2 \%$. Regardless of their sampling intensity (10.6 to 802.3 points per $\mathrm{km}^{2}$ ), i-Tree Canopy yielded higher standard errors when they assessed areas with higher tree canopy. Therefore, both the current extent of existing tree canopy and a target standard error should be considered when determining an optimal point sample size. So, a practical question is, "How do you anticipate what the UTC of the area is if you haven't conducted the UTC assessment yet?" In that case, a practitioner should start with a basic land cover map (such as the 2011 NLCD) or a tree canopy cover viewer (such as $i$-Tree Landscape) to get a general idea of the tree cover and then choose an appropriate point sample size based on that low-resolution information.

The other aspect of point sample size to consider is how it affects the accuracy of the UTC estimate (how close it is to the true value). In our case study of a relatively small geographic area, our estimate of UTC had well stabilized around $14.4 \%$ by the time we reached a sample size of 250 points. While this sample size might result in a tolerable standard error based on the theoretical curves shown in Figure 3, it may be an inadequate sample size to generate an accurate UTC estimate for a considerably larger geographic area or an area with highly variable land cover. For this reason, the practitioner should consider not just sample size (how many points) but also sampling intensity (how many points per unit land area). 


\section{Advantages and Disadvantages of the PI Method}

We used i-Tree Canopy to examine the PI method because it is widely available to urban forestry practitioners. Proprietary remote sensing data and software are not required, and analysts can be quickly trained to use the application regardless of technical background. In addition, practitioners can assess UTC and land cover for a relatively large geographic area within a few hours. The current version of $i$-Tree Canopy (version 6.1) also allows users to load previous $i$-Tree Canopy projects to analyze and monitor UTC changes over time. These features afford access to UTC and land cover assessment that might otherwise not be possible for small localities or organizations with limited budgets and technical expertise.

There are three notable limitations of $i$-Tree Canopy for urban forest planning and management. The first limitation is that the assessment does not provide detailed spatial information for where UTC exists in the study area. This lack of spatial information limits the utility of the tool for comparing tree canopy across the study area, for identifying spaces to plant new trees, and for prioritizing areas to protect existing tree canopy. With that said, it might be possible to coerce useful information out of $i$-Tree Canopy for these purposes by carefully customizing the land cover classes at the beginning of an assessment. For example, a land cover class called "available planting space" might be created, and any sampling point that randomizes to a map location where there would be no impediments to tree planting (e.g., a road, building, or recreational field is not present) could then be classified as such. However, this approach would require considerable knowledge of land use in the study area and still would not clarify where these opportunities exist, only how prevalent these opportunities are, as a percentage of the total land area.

A second limitation of $i$-Tree Canopy is the potential error due to visual misinterpretation of land cover types viewed on the aerial photo. When using i-Tree Canopy, we had difficulties interpreting sample points located in certain areas: (1) shrub or tall grass, (2) heavy shadows, (3) edges between two different land cover types, and (4) near objects shifted by relief displacement (a geographic distortion present in vertical aerial photographs whereby tall structures appear to tilt and obscure smaller objects such as trees near them). Richardson and Moskal (2014) also reported these imagery issues as potential sources of interpretation errors and pointed out that greater relief displacement would be a potential reason that $i$-Tree Canopy might overestimate tree canopy. Although human analysts currently have better acuity than computer algorithms for discerning the nuances of size, shape, shadow, and texture of tree versus nontree vegetation (Campbell and Wynne 2011), consideration must be given to imagery misinterpretation when training analysts to use $i$-Tree Canopy. In addition to human interpretation errors, Google Maps ${ }^{\text {TM }}$ often causes misinterpretations due to the different image qualities across a study area. In i-Tree Canopy, Google Maps ${ }^{\mathrm{TM}}$ displays a mosaicked set of images with various data specifications, including different temporal (leaf-on and leaf-off images) and spatial resolutions (Taylor and Lovell 2012). Although urban and metropolitan areas tend to have greater temporal and spatial resolutions in Google Maps $^{\mathrm{TM}}$, small or rural localities may encounter outdated or lower-quality imagery in i-Tree Canopy, making an accurate UTC assessment more difficult. With time, imagery in those areas will likewise improve.

A third limitation of $i$-Tree Canopy is that it offers only a simple random sampling scheme that estimates land cover across the whole study area. Simple random sampling might not be adequate when practitioners want to assess UTC in specific land uses (e.g., residential areas) or to compare UTC between two or more subregions (e.g., high- and low-density residential areas) within the study area (Ott and Longnecker 2010). Since urban trees and potential planting spaces tend to occur predominantly on private residential parcels, being able to differentiate these areas is critical for strategic tree planting and UTC conservation (Watkins et al. 2017). While $i$-Tree Canopy is not currently configured to permit sampling based on stratification of land use, such an analysis could be coerced from the application by first creating geographic information system (GIS) shapefiles for each land use in an area of interest and then analyzing them separately in the application.

\section{Advantages and Disadvantages of the IC Method}

A major advantage of the IC method for UTC assessment is the acquisition of a wall-to-wall classification map of UTC and land cover. This detailed map can be 
used to analyze the extent and distribution of tree canopy, identify potential tree planting sites within the study area, and monitor changes in tree canopy when collected over multiple time periods (McGee et al. 2012; King and Locke 2013). Although PI can also be used for UTC change detection, IC has the advantage of pinpointing UTC losses and gains in specific areas, whereas PI can only analyze net losses or gains overall. Additionally, an IC-based assessment can be combined with supplementary geospatial data in a GIS to boost its analytical power. For example, a UTC map can be merged with ground-based tree inventory data (e.g., species, trunk diameter, and condition) to identify particular portions of the canopy cover that might be at risk due to species composition, age, or health (Wiseman and McGee 2010). Incorporation of socioeconomic variables (e.g., population, education level, household income, and household type) can also be used to improve equity of tree canopy cover by identifying areas where low canopy coincides with underserved or vulnerable communities (Heynen et al. 2006). This is a specific capability of $i$-Tree Landscape, which offers users several sophisticated tools for analyzing the benefits associated with the mapped tree cover and then prioritizing tree planting based on a range of geographic and demographic criteria.

As with the PI method, inadequate spatial and spectral resolutions of images can also lead to significant errors in land cover classification with the IC method. A coarse spatial-resolution image is typically not recommended for UTC assessments due to the complexity of urban features (Walton 2008; Landry and $\mathrm{Pu}$ 2010). Mixed pixels comprising multiple ground features in coarse-resolution images may obscure detection of small trees and therefore lead to underestimation of tree canopy (Bhatta 2010). In looking at the tree cover map derived from the 2011 NLCD in $i$-Tree Landscape, it is apparent that, due to the low spatial resolution (30 m), NLCD could not detect small clumps of tree cover intermixed with land cover types in our study area (Figure 4). There were large swaths of the campus where none of the pixels were correctly classified as tree cover; conversely, there were areas that were misclassified as tree cover too. Over a large area, these contrasting errors would presumably average themselves out, but it appears that the NLCD tends to underestimate UTC in locations where trees are small and the percent canopy cover is low and highly dispersed (as in our study area). Increasing availability of higher spatial resolution images (less than $1 \mathrm{~m}$ ) and updated techniques for subpixel IC and object-based image analysis will lead to improvement in IC analysis of UTC (MacFaden et al. 2012; Riemann et al. 2016). Compared to the NLCD (30-m spatial resolution), the 1-m NAIP images like those used in the proprietary IC analysis of our study area can potentially provide 900 times more information about land cover (Chesapeake
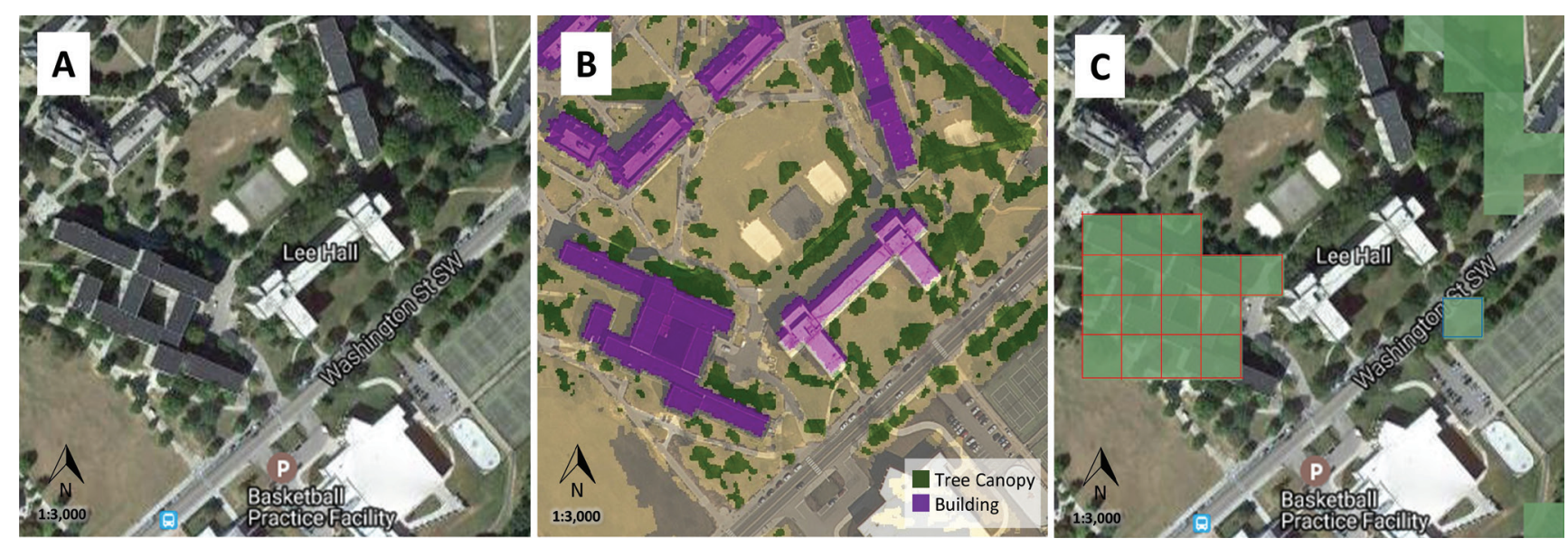

Figure 4. Map scenes showing the effect of imagery resolution on discernment of tree canopy from other land cover types on the Virginia Tech campus in Blacksburg, VA. Panel A: A high-resolution image of a portion of campus showing assorted trees, buildings, and open spaces as visible to the naked eye. Panel B: The computerized classification of the high-resolution (1-m) image showing good discernment of tree canopy (proprietary analysis). Panel C: Image pixels classified as tree canopy (green squares) from the low-resolution (30-m) NLCD data in $i$-Tree Landscape overlaid on the high-resolution imagery. Note that most of the tree cover in the center of the image was missed by the computerized classification, yet a large cluster of pixels over a large building (outlined in red) was misclassified as tree cover. Mixed pixels pose challenges for computerized IC on low-resolution images. 
Conservancy 2017). There are ongoing efforts to incorporate high-resolution land cover data into $i$-Tree Landscape (equivalent to our proprietary analysis), which will improve analysis capabilities over what is available currently with the lower resolution NLCD data. At the time of this article, high-resolution land cover maps for the entirety of the Chesapeake Bay Watershed and several major metropolitan areas across the United States had been integrated into $i$-Tree Landscape.

Just like human analysts in the PI method, the IC method is prone to some of the same errors in distinguishing tree canopy from land covers with similar spectral signatures. Shrubs and tall grasses have been reported to be difficult to distinguish from tree canopy in leaf-on seasons (Zhou and Troy 2008; MacFaden et al. 2012). In our evaluation of the low-resolution IC method of UTC analysis ( $i$-Tree Landscape), we found that groups of shrubs and artificially turfed athletic fields were often classified as trees and nontree vegetation, respectively. For this reason, integration of LiDAR data, which provide height information about land cover, can help to accurately distinguish between trees and other nontree vegetation and improve the accuracy of IC (O'NeilDunne et al. 2014; Parmehr et al. 2016). While becoming increasingly available, LiDAR data is costly and requires additional geospatial skills and software for processing.

The application $i$-Tree Landscape holds great promise as a widely available UTC assessment tool because most anyone with an internet connection and basic computer skills can obtain UTC and land cover data from it, albeit of an older vintage and with a limited range of analytical tools. The major limitation we find at this time is that the analyst does not have fine-scale control in delimiting the study area. Instead, the analyst has to delineate the study area using one of several predetermined boundaries - delimiting schemes built into the application. For our study area, we had to settle on a delimitation using US Census Block Groups, three of which overlaid our study area but did not match the boundaries precisely. As a result, we had to take additional steps for a more direct comparison of UTC estimates in our study area. Because localities and organization often wish to target programs and policies to particular landowners, a proprietary IC analysis of UTC might be preferable. However, $i$-Tree Landscape offers a low-cost alternative, particularly if the aim is to develop programs and policies targeted at geographic areas larger than the neighborhood scale.

\section{Limitations of Our Comparisons}

Although we found no statistically significant differences in the UTC of our study area across the time frames captured in the imagery analysis tools (2008 to 2011), time frame remains a limitation to an unequivocal comparison of the UTC assessment methods. Yet this time frame difference is also instructive from a practical standpoint. That is, any type of comparative analysis of tree and land cover using geospatial methods needs to be cognizant of the date and origin of the imagery. As an example, it is possible that a practitioner might wish to compare tree cover across multiple districts in a locality at a single point in time. In that case, it would be important to ensure comparability of the imagery. In our study, the date of the imagery could no doubt be a source of error in comparing the UTC assessment methods. Quantitatively, there were no statistical differences in estimates of tree canopy between the time frames. Qualitatively, we can also say that there were no major perturbances of tree cover by development, storms, or pests in the study area for the time frames bracketed by these imagery dates. Without question, there were gains and losses in tree cover from tree planting, canopy growth, and canopy mortality in the study area, but given that this is a relatively stable, middle-aged urban forest, we doubt that the observed differences (and similarities) in UTC and land cover across analysis methods were majorly influenced by canopy cover dynamics. Instead of the differences in image dates, we point to fundamental differences in the geospatial methods as the primary source of the variations that we observed: (1) mixed pixels, (2) relief displacements, (3) seasonal imagery differences (i.e., leaf-on vs. leaf-off imagery), and (4) the difficulty in distinguishing small-patch land cover types in close proximity to one another (imagery edge effects). Urban forestry practitioners must be aware of these sources of variation and take appropriate steps to minimize their influence on UTC assessments.

\section{Our Recommendations for UTC Assessment}

Although we observed differences in UTC estimates across the assessment methods in this study, we do not advocate for one method over the other because each has its relative strengths and weaknesses. Instead, 
we suggest that practitioners develop a fundamental understanding of not only the available methods and tools but also of how each might address their analytical needs in different ways. For rapid analysis of a large geographic area where the information needed is strictly the percentage of tree canopy cover relative to other land cover types, $i$-Tree Canopy (or a comparable PI tool) is a good choice. This information is useful for preliminary strategic planning or periodic benchmarking of land cover changes. When information about both the amount and distribution of tree canopy (and its interaction with other geo-oriented data) is also needed, then a wall-to-wall computerized classification of imagery would be a better choice. The analytical power of this type of assessment is much greater for this purpose, as evidenced by the capabilities of the $i$-Tree Landscape application. We recommend a wall-to-wall land cover assessment for those who need comprehensive and detailed information about tree canopy, which is important for long-range planning of tree planting and conservation as well as land use planning and local policy creation. $i$-Tree Canopy and $i$-Tree Landscape are also excellent platforms for enabling citizens to study their urban forests and for educating the public about urban forestry. Ongoing public investment in urban forest assessment tools is needed to empower localities of all sizes and resource capabilities to study their urban forests and make informed decisions about urban forestry policy, management plans, and practices that conserve and replenish tree canopy.

\section{CONCLUSION}

In this paper, we have provided an overview of the geospatial methods for UTC assessment that are commonly employed by urban forestry practitioners. Computerized IC of high-resolution aerial or satellite imagery is quickly becoming the gold standard for comprehensively assessing UTC and other land cover types over large geographic areas. While more commonplace than even five years ago, IC analysis of high-resolution imagery is still often out of reach - in terms of cost or technical complexity-for many small localities and nonprofit organizations seeking to understand their tree canopy and strategize for its conservation. The US Forest Service is addressing these barriers by creating web applications (i-Tree Canopy and i-Tree Landscape) that are free to the public and require limited technical capabilities. Our examination of i-Tree Canopy (a PI tool) on an urbanized college campus revealed that a high level of agreement in UTC and land cover estimates can be achieved in comparison to computerized classification of high-resolution imagery. Where the land cover map is derived from the low-resolution 2011 NLCD, $i$-Tree Landscape appears to underestimate UTC, but its capabilities will undoubtedly improve as more high-resolution maps are incorporated into the tool. Information about tree canopy and land cover is fundamental to urban forestry and has numerous applications for understanding the structure and function of the urban forest and its management needs. A greater understanding of UTC assessment methods and careful choice of assessment tools will advance these efforts.

\section{LITERATURE CITED}

Bhatta, B. 2010. Analysis of Urban Growth and Sprawl from Remote Sensing Data. Springer, Verlag, Berlin, Heidelberg, Germany. 172 pp.

Campbell, J.B., and R.H. Wynne. 2011. Introduction to Remote Sensing. Guilford Press, New York, USA. 667 pp.

Chesapeake Conservancy. 2017. Land Cover Data Project. Chesapeake Conservancy, Annapolis, Maryland, USA. Accessed July 2018. $<$ http://chesapeakeconservancy.org/ conservationinnovation-center/high-resolution-data/land-cover-data-project>

Dwyer, J.F., E.G. McPherson, H.W. Schroeder, and R.A. Rowntree. 1992. Assessing the benefits and costs of the urban forest. Journal of Arboriculture 18(5): 227-234.

Eyre, F.H. 1980. Forest Cover Types of the United States and Canada. Society of American Forests, Bethesda, Maryland, USA. 488 pp.

Greenfield, E.J., D.J. Nowak, and J.T. Walton. 2009. Assessment of 2001 NLCD percent tree and impervious cover estimates. Photogrammetric Engineering \& Remote Sensing 75(11): 1279-1286.

Heynen, N., H.A. Perkins, and P. Roy. 2006. The political ecology of uneven urban green space: The impact of political economy on race and ethnicity in producing environmental inequality in Milwaukee. Urban Affairs Review 42(1): 3-25.

Hostetler, A.E., J. Roan, D. Martin, V. DeLauer, and J. O’NeilDunne. 2013. Characterizing tree canopy loss using multisource GIS data in Central Massachusetts, USA. Remote Sensing Letters 4(12): 1137-1146.

Kaspar, J., D. Kendal, R. Sore, and S.J. Livesley. 2017. Random point sampling to detect gain and loss in tree canopy cover in response to urban densification. Urban Forestry \& Urban Greening 24: 26-34.

Kimball, L.L., P.E. Wisman, S.D. Day, and J.F. Munsell. 2014. Use of urban tree canopy assessments by localities in the Chesapeake Bay Watershed. Cities and the Environment 7(2): Article 9.

King, K.L., and D.H. Locke. 2013. A comparison of three methods for measuring local urban tree canopy cover. Arboriculture \& Urban Forestry 39(2): 62-67.

Landry, S., and R. Pu. 2010. The impact of land development regulation on residential tree cover: An empirical evaluation 
using high-resolution IKONOS imagery. Landscape and Urban Planning 94(2): 94-104.

MacFaden, S.W., J.P.M. O’Neil-Dunne, A.R. Royar, J.W.T Lu, and A.G. Rundel. 2012. High-resolution tree canopy mapping for New York City using LiDAR and object-based image analysis. Journal of Applied Remote Sensing 6(1): 1-23.

McGee, J.A., S.D. Day, R.H. Wynne, and M.B. White. 2012. Using geospatial tools to assess the urban tree canopy: decision support for local government. Journal of Forestry 110(5): 275-286.

McPherson, E.G., J.R. Simpson, Q. Xiao, and C. Wu. 2011. Million trees Los Angeles canopy cover and benefit assessment. Landscape and Urban Planning 99(1): 40-50.

Myeong, S., D.J. Nowak, P.F. Hopkins, and R.H. Brock. 2001. Urban cover mapping using digital high-spatial resolution aerial imagery. Urban Ecosystems 5(4): 243-256.

Nowak, D.J., and J.F. Dwyer. 2007. Understanding the benefits and costs of urban forest ecosystem. pp. 25-46. In: J.E. Kuser (Ed.). Urban and Community Forestry in the Northeast. Springer, New York, New York, USA.

Nowak, D.J., and E.J. Greenfield. 2010. Evaluating the National Land Cover Database tree canopy and impervious cover estimates across the conterminous United States: A comparison with photo-interpreted estimates. Environmental Management 46(3): 378-390.

Nowak, D.J., and E.J. Greenfield. 2012. Tree and impervious cover change in U.S. cities. Urban Forestry \& Urban Greening 11(1): 21-30.

Nowak, D.J., E.J. Greenfield, R.E. Hoehn, and E. Lapoint. 2013. Carbon storage and sequestration by trees in urban and community areas of the United States. Environmental Pollution 178: 229-236.

Nowak D.J., R.A. Rowntree, E.G. McPherson, S.M. Sisinni, E.R. Kerkmann, and J.C. Stevens. 1996. Measuring and analyzing urban tree cover. Landscape and Urban Planning. 36(1): 49-57.

O’Neil-Duune, J., S. MacFaden, and A. Royar. 2014. A versatile, production-oriented approach to high-resolution tree-canopy mapping in urban and suburban landscapes using GEOBIA and data fusion. Remote Sensing 6(12): 12837-12865.

Ott, R.L., and M. Longecker. 2010. An Introduction to Statistical Methods and Data Analysis. Brooks/Cole Cengage Learning, Pacific Grove, California, USA. 1273 pp.

Parmehr, E.G., M. Amati, E.J. Taylor, and S.J. Livesley. 2016. Estimation of urban tree canopy cover using random point sampling and remote sensing methods. Urban Forestry \& Urban Greening 20: 160-171.

Richardson, J.J., and L.M. Moskal. 2014. Uncertainty in urban forest canopy assessment: Lessons from Seattle, WA, USA. Urban Forestry \& Urban Greening 13: 152-157.

Riemann, R., G. Liknes, J. O’Neil-Dunne, C. Toney, and T. Lister. 2016. Comparative assessment of methods for estimating tree canopy cover across a rural-to-urban gradient in the mid-Atlantic region of the USA. Environmental Monitoring and Assessment 188: 297.

Taylor, J.R., and S.T. Lovell. 2012. Mapping public and private spaces of urban agriculture in Chicago through the analysis of high-resolution aerial images in Google Earth. Landscape and Urban Planning 108: 57-70.
Ucar, Z., P. Bettinger, K. Merry, J. Siry, J.M. Bowker, and R. Akbulut. 2016. A comparison of two sampling approaches for assessing the urban forest canopy cover from aerial photography. Urban Forestry \& Urban Greening 16: 221-230.

United States Department of Agriculture. 2015. National Agriculture Imagery Program (NAIP) Information Sheet. USDA Farm Service Agency, Washington D.C., USA. Accessed July 2018. <http://www.fsa.usda.gov/Internet/FSA_File/ naip_info_sheet_2015.pdf>

US Forest Service. 2011. $i \square$ Tree Canopy Technical Notes. US Forest Service, Washington D.C., USA. Accessed July 2018. $<$ http://canopy.itreetools.org/resources/iTree_Canopy_ Methodology.pdf>

US Forest Service. 2016. Urban Tree Canopy Assessment Program. US Forest Service, Washington D.C., USA. Accessed July 2018. <http://www.fs.fed.us/research/highlights/highlights display.php?in_high_id=222>

US Geological Survey. 2017. National Land Cover Database 2011 (NLCD 2011). Accessed July 2018. <http://www.mrlc. gov/nlcd11_data.php>

Virginia Information Technologies Agency. 2016. Orthoimagery. Virginia Information Technologies Agency, Chester, Virginia, USA. Accessed July 2018. <http://www.vita.virginia.gov/ integrated-services/vgin-geospatial-services/orthoimagery>

Walker, M., A. Sakazaki, R. Eckenrode, and G. Dahle. 2017. Ecosystem Benefits of Tree City USA Cities in West Virginia. West Virginia University, School of Natural Resources, Arboriculture and Urban Forestry Program, Morgantown, West Virginia, USA. < https://www.wvforestry.com/pdf/ WV\%20TCUSA\%20iTree\%20Canopy\%20Survey-\%20 WVU\%209-13-2017.pdf>

Walton, J.T. 2008. Difficulties with estimating city-wide urban forest cover change from national, remotely-sensed tree canopy maps. Urban Ecosystems 11(1): 81-90.

Walton, J.T., D.J. Nowak, and E.J. Greenfield. 2008. Assessing urban forest canopy cover using airborne or satellite imagery. Arboriculture \& Urban Forestry 34(6): 334-340.

Watkins, S.L., S.K. Mincey, J. Vogt, and S.P. Sweeney. 2017. Is planting equitable? An examination of the spatial distribution of nonprofit urban tree-planting programs by canopy cover, income, race, and ethnicity. Environment and Behavior 49(4): 452-482

Wiseman, P.E., and J. McGee. 2010. Taking stock: Assessing urban forests to inform policy and management. Virginia Forests Magazine 65(4): 4-7.

Xiao, Q., E.G. McPherson, S.L. Ustin, and M.E. Grismer. 2000. A new approach to modeling tree rainfall interception. Journal of Geophysical Research: Atmospheres 105(D23): 29173-29188.

Zhou, W., and A. Troy. 2008. An object-oriented approach for analyzing and characterizing urban landscape at the parcel level. International Journal of Remote Sensing 29(11): 3119-3135.

\section{ACKNOWLEDGEMENTS}

Funding to support this research was made possible in part by the Virginia Agricultural Experiment Station and the McIntire 
Stennis program of the National Institute of Food and Agriculture, US Department of Agriculture.

\author{
Won Hoi Hwang (corresponding author) \\ Department of Forest Resources \& Environmental Conservation \\ Virginia Tech \\ Blacksburg, VA, USA \\ whwang@vt.edu \\ P. Eric Wiseman \\ Department of Forest Resources \& Environmental Conservation \\ Virginia Tech \\ Blacksburg, VA, USA
}

\section{Conflicts of Interest:}

The authors reported no conflicts of interest.

Résumé. L'évaluation de la canopée des arbres urbains (CAU) est essentielle à la compréhension de la structure et aux fonctions des forêts urbaines pour l'élaboration de stratégies de gestion. Les techniques de géolocalisation sont couramment utilisées pour l'évaluation des CAU bien que leurs potentiels et leurs limites ne soient pas toujours évidentes aux praticiens en foresterie urbaine. Cette recherche fournit une vue d'ensemble de deux méthodes de base pour l'évaluation en géolocalisation de CAU : la photo-interprétation (PI) et la classification d'images informatisées (CI). Ces méthodes furent évaluées dans le contexte d'une étude de cas pour un campus collégial urbanisé de l'Est des États-Unis. L'application en ligne i-Tree Canopy est une méthode PI qui a recours à un échantillonnage statistique de points pour estimer le couvert terrestre. Afin d'examiner l'impact de la taille des points échantillonnés sur la précision et la certitude des estimés de couvert terrestre, nous réalisâmes des évaluations reproduites de manière indépendante de notre étude de cas avec des points échantillonnés de taille variable. Nous comparâmes alors ces résultats avec deux méthodes CI soit une analyse propriétaire utilisant des images à haute résolution spatiale et une analyse avec une basse résolution en recourant à l'application en ligne $i$-Tree Landscape. Avec i-Tree Canopy, l'estimé de la CAU pour notre étude de cas se stabilisa à un décevant $14.7 \%$ lorsque la taille des points d'échantillonnage atteignait 100 points alors que plus de 500 points furent nécessaires afin d'atteindre une marge d'erreur acceptable inférieure à $1.7 \%$. En comparaison, l'imagerie à haute résolution (considérée comme la méthode d'évaluation la plus poussée) établit la CAU du secteur à l'étude à $16.1 \%$, tandis que i-Tree Landscape sous-estima considérablement cette dernière à $11.3 \%$. Les sources potentielles de variation de ces estimés, relativement à des considérations pratiques en vue du choix de la méthode appropriée d'évaluation de la CAU, furent examinées.

Zusammenfassung. Die Untersuchung von Kronen urbaner Bäume (UTC) ist wichtig für das Verständnis der Struktur und Funktion urbaner Forste und für Entwicklung von Managementstrategien. Raumbezogene Techniken werden routinemäßig für die Kronenuntersuchung (UTC) verwendet, obwohl ihre Möglichkeiten und Begrenzungen für die Praktiker in der urbanen Forstwirtschaft nicht so offensichtlich sind. Dieses Papier liefert einen Überblick zu zwei grundlegenden Methoden der räumlichen Kronenmessung: Fotointerpretation (PI)und Klassifikation von computer-generierten Bildern (IC). Diese Methoden wurden durch eine Fallstudie an einem urbanisiertem College Campus in den östlichen Vereinigten Staaten bewertet. Die Webbasierte Applikation i-Tree Canopy ist eine PI-Methode, die statistische Punkte zur Schätzung der Landbedeckung sammelt. Um die Auswirkungen der Größe der gesammelten Punkte auf Akkuresse und Sicherheit über die Landbedeckung zu schätzen, führten wir zwei unabhängig voneinander wiederholte Überprüfungen unserer Studie mit verschiedenen Punktsammelgrößen durch. Wir verglichen die Ergebnisse mit zwei IC-Methoden: eine Eigentums-Analyse unter Verwendung von Bildern mit hoher räumlicher Auflösung und einer analyse mit geringer räumlicher Auflösung unter Verwendung der web-basierten Applikation $i$-Tree Landscape. Mit $i$-Tree Canopy stabilisierte sich die geschätzte Kronenfläche in unserer untersuchten Fläche bei durchschnittlich $14.7 \%$, wenn die Punktsammelgröße der erfassten Punkte 100 Punkte erreichte, aber es erforderte mehr als 500 Punkte, um einen tolerablen Standortfehler von weniger als $1.7 \% \mathrm{zu}$ erzielen. Im Vergleich schätze die hoch auflösende Bildgebung (angesehen als die meist robuste Form der Untersuchung) in der Studienfläche $16.1 \%$ UTC und i-Tree Landscapeunterschätzte die UTC deutlich mit 11.3\%. Mögliche Ursachen für die Variationen dieser Schätzungen gemeinsam mit praktischen Überlegungen für die Wahl einer angemessenen UTC Untersuchungsmethode werden diskutiert.

Resumen. La evaluación del dosel arbóreo urbano (UTC) es esencial para comprender la estructura y función de los bosques urbanos y para diseñar estrategias de manejo. Las técnicas geoespaciales se usan rutinariamente para la evaluación del UTC. Sin embargo, sus capacidades y limitaciones pueden no ser evidentes para los profesionales de la silvicultura urbana. Este documento proporciona una visión general de dos métodos principales de evaluación UTC geoespacial: interpretación fotográfica (PI) y clasificación de imágenes computarizadas (IC). Estos métodos fueron evaluados a través de un estudio de caso de un campus universitario urbanizado en el este de los Estados Unidos. La aplicación basada en la web i-Tree Canopy es un método PI que utiliza el muestreo de puntos estadísticos para estimar la cobertura del suelo. Para examinar el efecto del tamaño de la muestra puntual en la precisión y certeza de las estimaciones de la cobertura del suelo, realizamos evaluaciones replicadas de forma independiente de nuestra área de estudio en varios tamaños de muestra puntuales. Comparamos estos hallazgos con dos métodos de CI: un análisis patentado usando imágenes de alta resolución espacial y un análisis de baja resolución espacial usando la aplicación basada en la web i-Tree Landscape. Con i-Tree Canopy, la estimación de UTC en nuestra área de estudio se estabilizó en un promedio de $14.7 \%$ cuando el tamaño de la muestra puntual alcanzó los 100 puntos, pero requirió más de 500 puntos para alcanzar un error estándar tolerable de menos del 1.7\%. En comparación, las imágenes de alta resolución (consideradas la forma más sólida de evaluación) estimaron UTC en el área de estudio en $16.1 \%$, e $i$-Tree Landscape subestimó sustancialmente UTC en $11.3 \%$. Se discuten las posibles fuentes de variación en estas estimaciones, junto con consideraciones prácticas para elegir un método de evaluación UTC apropiado. 